\title{
Simulation of Daily Rainfall Data using Articulated Weather Generator Model for Seasonal Prediction of ENSO-Affected Zones in Indonesia
}

\author{
Andung Bayu Sekaranom ${ }^{1,2}$ Emilya Nurjani ${ }^{1}$, Rika Harini ${ }^{1}$ and Andi Syahid Muttaqin ${ }^{3}$ \\ ${ }^{1}$ Faculty of Geography, Universitas Gadjah Mada, Bulaksumur 55281 Indonesia \\ ${ }^{2}$ Disaster Research Center, Universitas Gadjah Mada, Bulaksumur 55281 Indonesia \\ ${ }^{3}$ Faculty of Agriculture, Universitas Gadjah Mada, Bulaksumur 55281 Indonesia
}

Received: 2019-11-23 Accepted: 2020-06-30

Keywords:

El-Nino Southern Oscillation; synthetic rainfall data;

weather generator model

Surakarta.

Correspondent email:

andungbayu@geo.ugm.ac.id

\begin{abstract}
Synthetic rainfall simulation using weather generator models is commonly used as a substitute at locations with incomplete or short rainfall data. It incorporates a method that can be developed into forecasts of future rainfall. This study was designed to modify a rainfall prediction system based on the principles of weather generator models and to test the validity of the modelling results. It processed the data collected from eight rain stations in zones affected by El-Nino Southern Oscillation (ENSO). A large-scale predictor, that is, SST prediction data in the Nino 3.4 region over the Pacific Ocean was used as the influencing variable in projecting rainfall for the following six months after the predefined dates. Rainfall data from weather stations and SST in 1960-2000 were analyzed to identify the effects of ENSO and build a statistical model based on the regression function. Meanwhile, the model was validated using the data from 2001 to 2007 by backtesting six months in a row. The analysis results showed that the model could simulate both low rainfall in the dry season and high one in the rainy season. Validation by the student's t-test confirmed that the six-month synthetic rain data at nearly all observed stations was homogenous. For this reason, the developed model can be potentially used as one of the season prediction systems.
\end{abstract}

๑2020 by the authors. Licensee Indonesian Journal of Geography, Indonesia.

This article is an open access at ticle distributed under the terms and conditions of the Creative Commons

Attribution(CC BY NC) licensehttps://creativecommons.org/licenses/by-nc/4.0/.

\section{Introduction}

Nowadays, there has been an immense number of climate change impacts in Indonesia (Sekaranom \& Masunaga, 2017; Sekaranom, Nurjani, \& Pujiastuti, 2018). As a result, in most regions floods, drought, sea-level rise and forest fires have increased dramatically in frequency (Marfai, Sekaranom, \& Cahyadi, 2015; Marfai, Sekaranom, \& Ward, 2015). Climate change mainly contributes to elevated precipitation rates in the rainy season but decreased amounts of rainfall in the dry season (Chung \& Power, 2014; Ummenhofer, D'Arrigo, Anchukaitis, Buckley, \& Cook, 2013). That said, agriculture is projected to be the most severely affected sector because extremely different rains in alternating dry and rainy seasons result in crop failure (Iglesias \& Garrote, 2015; Nurjani, Harini, Sekaranom, \& Mutaqqin, 2020). Also, the economic sector is broadly affected as climate change-induced floods damage infrastructure and inundate residential and industrial areas (Marfai, Sekaranom, \& Ward, 2015).

Weather and climate data enable the estimation of climate change impact and corresponding mitigation, as well as the development of adaptation strategies (Iglesias \& Garrote, 2015; Meinke \& Stone, 2005). A sufficiently long record, which is more than 30 years, is generally required (Meinke \& Stone, 2005). However, most data in Indonesia do not have a long observation period (Sekaranom, Nurjani, Hadi, \& Marfai, 2018). In cases where only short observational data are available in the field, simulated data called synthetic rainfall data can be used instead (Richardson \& Wright, 1984).
Synthetic rainfall data can be obtained from shorter observation times as a basis for statistical or numerical model calculations(Richardson \& Wright, 1984). Statistical methods are more straightforward and require less computational capacity than the numerical model (Sekaranom \& Nurjani, 2019). A statistical method that produces synthetic data is termed as the weather generator model(Ivanov, Bras, \& Curtis, 2007; Richardson \& Wright, 1984). Weather generator models simulate climatic parameters according to their statistical characteristics, as obtained from observation data. This simulation is based on several statistical parameters, namely mean value, statistical data distribution and the probability of a value or an event to occur (Wilby, 1999). Weather generator models have been widely applied in many fields, including water resources analysis and hydrometeorological disasters (Ivanov et al., 2007).

Weather generator models assume that the statistical characteristics of a meteorological parameter in an area are constant and do not change (Wilby, 1999). For example, at the same location, there is no difference in rainfall today and ten years ago. For this reason, the model cannot simulate any changes in statistical properties that may have occurred. Weather generator models, thereby, cannot be used as a basis in analyses involving future climate change.

From a meteorological perspective, large-scale changes in weather and climate parameters most likely affect the same parameters in a smaller area of coverage. For instance, as a 
result of climate change, sea-surface temperature (SST) shifts in the Pacific region modify the El-Nino and La-Nina states in the El-Nino Southern Oscillation (ENSO), which in turn influence rainfall occurrences in some parts of Indonesia (Jourdain et al., 2013; Sekaranom, Nurjani, \& Pujiastuti, 2018). If the sea surface temperatures in the eastern Pacific Ocean rise, a stronger El-Nino potentially occurs and brings about widespread drought. On the contrary, a warming of the western Pacific Ocean surface can lead to a stronger La-Nina, which causes flooding over increasingly more extensive areas in some Indonesian regions (Grimm \& Tedeschi, 2009; Sekaranom \& Masunaga, 2019; Sekaranom, Nurjani, \& Pujiastuti, 2018).

Contributing weather and climate factors can be fundamentally used as the calculation variables in weather generator models (Wilks, 1999). As an example, changes in the magnitude of ENSO are represented by sea surface temperature (SST) anomalies in the Nino 3.4 region in the Pacific Ocean (Chowdhury \& Beecham, 2013). This particular variable can be considered as a parameter in rainfall distribution and probability change. This contributing factor can be integrated into the weather generator model. This paper is intended to explain the development of Articulated weather generator for seasonal climate prediction (AWGenSCP) model (Sekaranom \& Nurjani, 2019). The model integrates regional weather and climate parameters into a weather generator system (Sekaranom \& Nurjani, 2019). In this paper, the AWGenSCP model is designed to simulate weather in the following six months based on ENSO prediction data and weather and climate parameters. This paper further explains the development of the basic concepts of integrating regional weather and climate parameters into AWGenSCP and describes the results of the model validation.

\section{The Methods}

This study reproduced rainfall data in some ENSOaffected areas in Indonesia as an example of simulation. Increased and reduced rainfalls during La-Nina and El-Nino characterize these regions (Sekaranom, Nurjani, \& Pujiastuti, 2018). This study backtested the modelled rain data for six months in a row after each of the predetermined times of analysis. The baseline data from 1960-2000 was used to build the statistical properties of the model. Furthermore, backtesting was carried out starting from 2001 to 2007 for particular locations. Records of rainfall during this period were used to validate the created model. More specifically, the research method is as follows:

\section{Data}

AWGenSCP simulates two categories of data. The first category is large-scale predictors that influence regional weather and climate. In this study, SST prediction in the Nino 3.4 zone was used to represent the effects of ENSO. ENSO variability was selected because it has the broadest range of influence compared with other regional weather and climate dynamics in Indonesia (Sekaranom, Nurjani, \& Pujiastuti, 2018). SST prediction for this zone was obtained from the NOAA National Centers for Environmental Prediction (NCEP), which is a coupled forecast system model (CFSv2 model) that can be downloaded at http:// www.cpc.ncep.noaa.gov/products/CFSv2CFSv2seasonal.sht $\mathrm{ml}$. Figure 1 presents an example of SST data in the Nino 3.4 zone during the baseline period. In general, $+/-1^{\circ} \mathrm{C}$ is the threshold for determining the El-Nino and La-Nina states. A weather pattern is categorized as El-Nino when SST anomaly reaches $>1^{\circ} \mathrm{C}$, whereas La Nina is considered when SST anomaly reaches $<1^{\circ} \mathrm{C}$ (Chowdhury \& Beecham, 2013; Grimm \& Tedeschi, 2009).

The second category is the rain station data, which

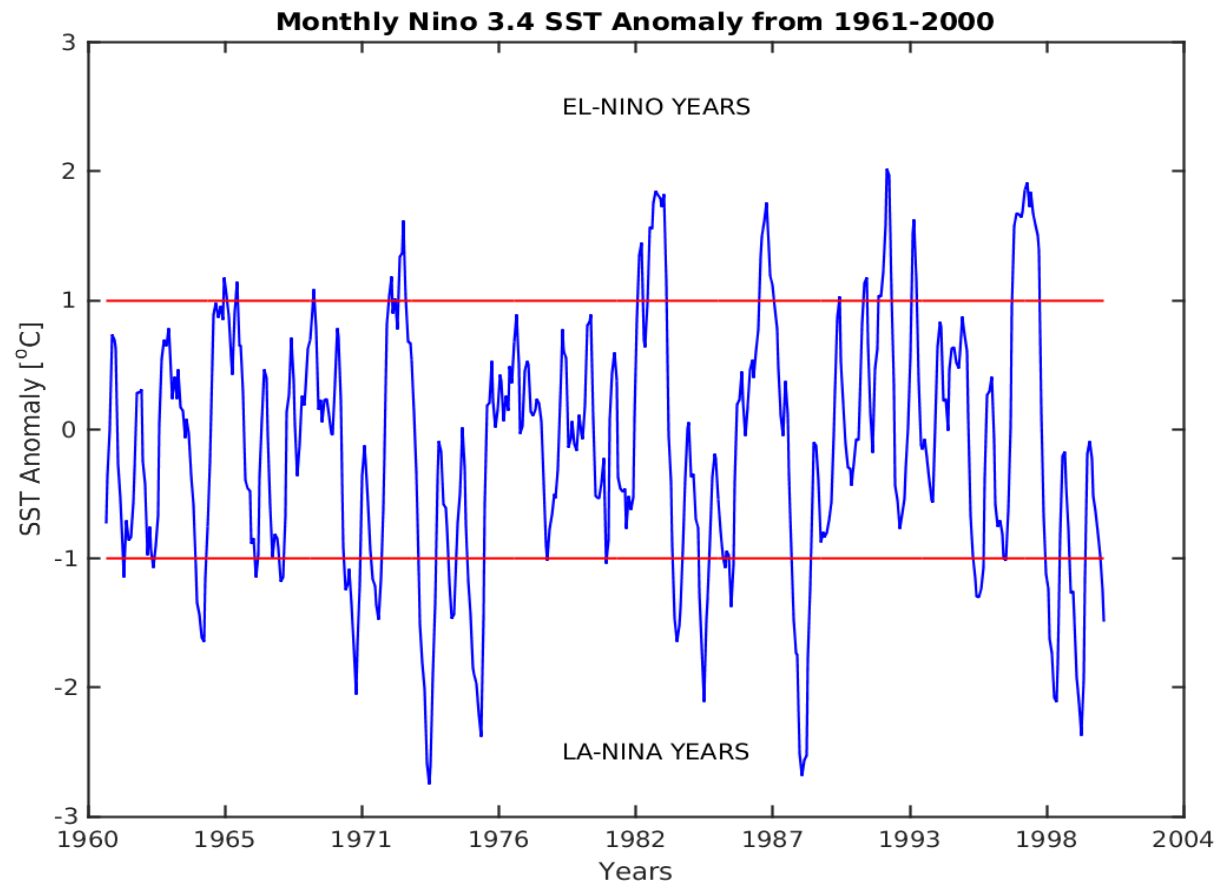

Figure 1. Sea surface temperature anomaly in the Nino 3.4 zone during the baseline period (1961-2000). La-Nina is characterized by colder SST anomaly $\left(<-1^{\circ} \mathrm{C}\right)$, while El-Nino by warmer SST anomaly $\left(>1^{\circ} \mathrm{C}\right)$. Source: NCEP-coupled forecast system model version 2 (CFSv2 model) 
Table 1. Rain station data used in the analysis and correlation analysis between rainfall and SST in the Nino 3.4 zone. The highest seasonal correlation values are indicated by bold letters (Source: Data analysis)

\begin{tabular}{cccccccc}
\hline & & & & \multicolumn{4}{c}{ SST anomaly in Nino 3.4 } \\
\cline { 5 - 8 } ID & Stations & Lon & Lat & & \multicolumn{4}{c}{ Seasonal Correlation } \\
\cline { 5 - 8 } & & & & DJF & MAM & JJA & SON \\
\hline a & Yogyakarta & 110.37 & -7.77 & -0.05 & -0.21 & -0.11 & -0.45 \\
b & Kebumen & 109.47 & -7.64 & 0.05 & -0.13 & -0.15 & -0.44 \\
c & Semarang & 110.39 & -6.99 & 0.13 & -0.21 & -0.14 & -0.39 \\
d & Denpasar & 115.15 & -8.67 & 0.01 & -0.12 & -0.11 & -0.41 \\
e & Lombok & 116.33 & -8.63 & 0.00 & -0.19 & -0.19 & -0.44 \\
f & Bima & 118.75 & -8.47 & -0.03 & -0.21 & -0.17 & -0.43 \\
g & Banyuwangi & 114.27 & -8.27 & -0.06 & -0.07 & -0.11 & -0.43 \\
h & Jepara & 110.66 & -6.62 & -0.07 & -0.23 & -0.09 & -0.38 \\
\hline
\end{tabular}

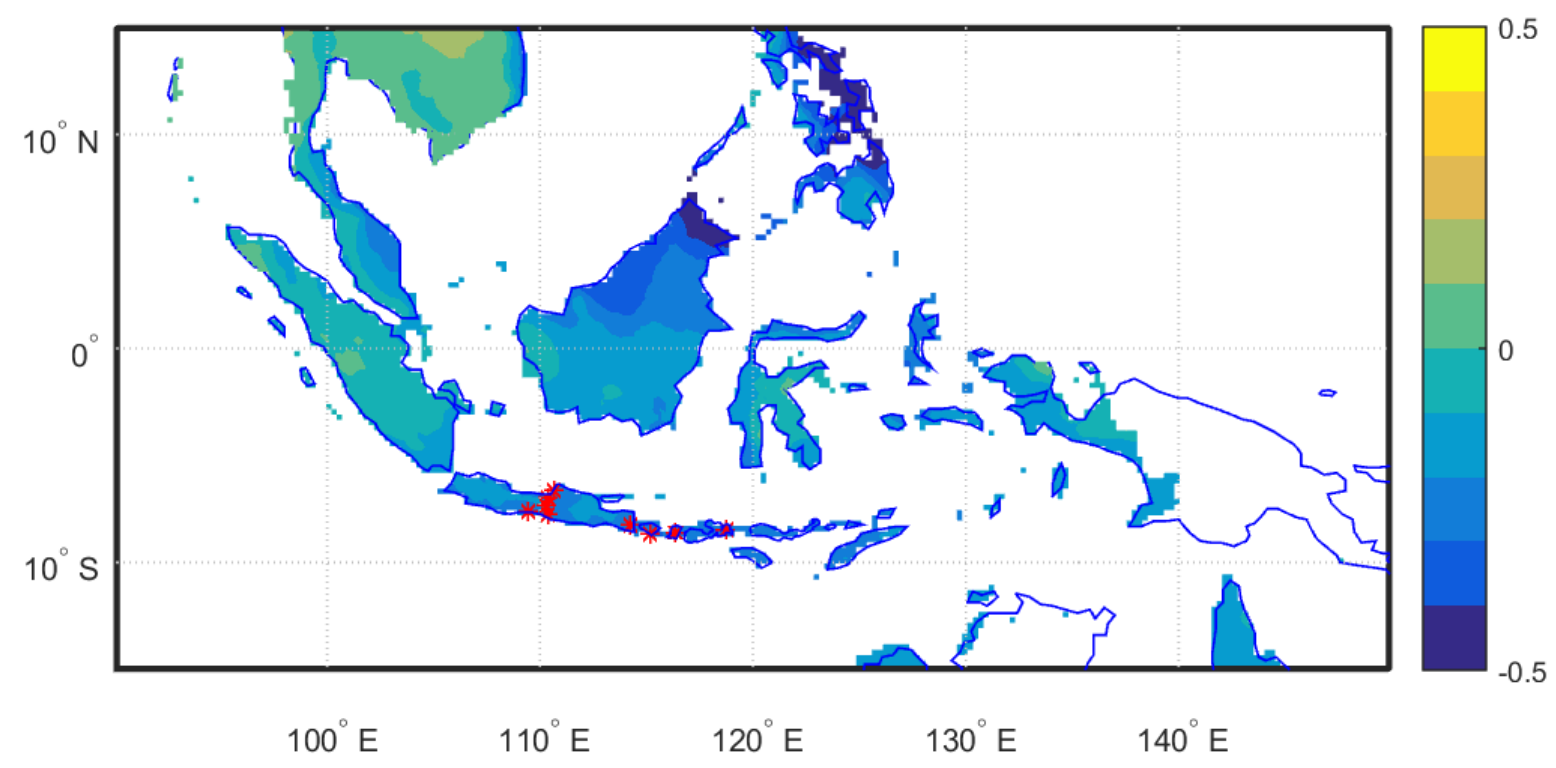

Figure 2. Rain station data used in the analysis and correlation analysis between rainfall and SST in the Nino 3.4 zone. The colour bar represent the correlation between rainfall and Nino 3.4 SST in SON.

represents the weather and climate at the local level as predictand variables). Rain observation stations in regions receiving the most substantial influence of ENSO were selected for the rainfall simulations. At the initial stage, the correlation analysis between rainfall and SST in the Nino 3.4 zone sought to determine locations that were intensely affected by ENSO. It was carried out depending on the season, namely a) December-January-February (DJF), b) March-April-May (MAM), c) June-July-August (JJA) and d) September-October-November (SON). At the final stage, eight (8) rain stations from the Meteorology, Climatology and Geophysical Agency (BMKG) were chosen for further analysis (Table 1 and Figure 2).

The seasonal correlation analysis revealed that the highest correlation at all rain stations occurred in SeptemberOctober-November (SON). This correlation was negative because of the high SST in the Nino 3.4 zone, typifying an ElNino condition in which rainfall in some parts of Indonesia tends to decrease (Sekaranom, Nurjani, \& Pujiastuti, 2018). It is mainly correlated to the beginning of the rainy season.
ENSO significantly modifies, or particularly delays, the start of the rainy season at the study locations. Meanwhile, at the peak of the rainy season (December-January-February or DJF), the correlation was at its lowest, indicating that the effect of ENSO at this time is considerably weak.

\section{The Methods}

The method used in AWGenSCP is developed from the basic statistical approach incorporated in the Weather Generator Mode (Sekaranom \& Nurjani, 2019). In the Weather Generator Model, the fundamental assumption is that the probability of an event occurring in the future depends on the conditions in the past and the present (Sekaranom \& Nurjani, 2019). For example, the probability of rain to occur tomorrow is strongly attributable to today's weather and climate. Thereby, it is formulated as a Markov Chain (Richardson \& Wright, 1984; Wilby, 1999), that is, a process where: 
$P\left(X_{t+1}=S \mid X_{t}=S_{t}, X_{t-1}=S_{t-1, \ldots,} X_{0}=S_{0}\right)=P\left(X_{t+1}=s\right.$ [Could greveal changes in data probability. This approach enabled the prediction of the statistical distribution of rainfall

with $S_{x} S_{t}, S_{0}$ representing rainy/non-rainy day, $P\left(X_{t+1}\right)$ denoting the chance of rain on the next day and $P\left(X_{\mathrm{t}}\right)$ as the chance of rain at the present day, as obtained from the actual rainfall data and the function of days of rain (Rd) and rainfall $(\mathrm{Rr})$. The formula is as follows:

$$
\begin{gathered}
R d=\left\{\begin{array}{c}
1 \text { if } R r>0 \\
0
\end{array}\right. \\
P(X t)=\frac{\sum_{n} R d}{n}
\end{gathered}
$$

In the developed model, whether or not rain occurs in the next one day depends on a random number (Sekaranom \& Nurjani, 2019). Rainfall occurs if it exceeds a specific value above a threshold. If the random number is less than the specified limit and shows no rain event the next day, then the probability of rain is zero $(0 \mathrm{~mm} /$ day $)$. However, if the random number exceeds the specified threshold for probability, then the simulation results most likely show a rainy day.

If the simulation indicates a rainy day, then the next step is to determine rainfall depth randomly according to rainfall data distribution. In this model, the rainfall distribution is based on gamma distribution fitting. This process produces the shape $(\mathrm{k})$ and scale $(\theta)$ parameters in gamma probability distribution function:

$$
f\left(x_{x} k, \theta\right)=\frac{1}{\Gamma(k) \theta^{k}} x^{k-1} e^{-\frac{x}{\theta}}
$$

where $f\left(x_{x}, \theta\right)$ is gamma distribution function and $\Gamma(x)$ is a gamma function for a random value $x$. The amount of daily rain was determined through a random function, which randomly selects a value based on the gamma probability distribution function. Therefore, rainfall simulation by weather generator model primarily refers to conditional probability, which is:

$$
R=\left\{\begin{array}{c}
\Gamma(\mathrm{x}) \|(\mathrm{x} \sim \mathrm{U}([0,1])) \\
0
\end{array} \text { if } x>1-P(X t)\right.
$$

In the AWGenSCP model, the influencing variables on the regional scale serve as predictors, which are divided into two functions, namely how predictors affect the probability of rainfall events and how they affect the distribution of rainfall (Sekaranom \& Nurjani, 2019). For instance, La-Nina allows rain to occur more frequently, increasing the likelihood of rain (Jourdain et al., 2013). In terms of distribution, La-Nina can also increase the frequency of highintensity rain events, resulting in a shift in gamma distribution.

In this model, the question of how predictors affect the probability of rain was answered by the regression function. Using the baseline data and the regression between large scale predictors (SST in the Nino 3.4 zone), the researchers events using the large scale predictors-in this case, is SST projection in the Nino 3.4 zone for the following six months after the time of release-using the formula below:

$$
P\left(X_{\mathrm{t}+1}\right)=\alpha_{p}+\beta_{p} \gamma_{t}
$$

where the probability of a rainy day in the future $P\left(X_{t+1}\right)$ is a function of intercept ${ }^{\alpha_{P}}$ and $\beta_{P}$ generated by a simple regression model whose value of large-scale predictor $\left({ }^{\gamma}\right)$ is determined. Regression models were also applied in projecting changes in the gamma distribution, which in detail, was divided into shape parameter $\left({ }^{k_{t+1}}\right)$ and scale parameter $\left({ }^{\theta_{t+1}}\right)$ in the predictions for the next day. The prediction of change in scale parameter and shape parameter in the linear regression model using intercept ${ }^{\alpha_{k v} \beta_{k}}$ and $\alpha_{\theta}, \beta_{\theta}$ is expressed by the following equation:

$$
\begin{aligned}
& k_{t+1}=\alpha_{k}+\beta_{k} \gamma_{t} \\
& \theta_{t+1}=\alpha_{\theta}+\beta_{\theta} \gamma_{t}
\end{aligned}
$$

The end result of changes in probability and shape and scale parameters-based on the predictors of six-month rainfall-is a synthetic rain data that follows the statistical changes occurring in the predictor variable. Data distribution must take into account the fact that rainfall data statistically varies throughout the year, specifically in dry and rainy seasons. In this study, data distribution was analyzed into a 3 -month time to determine changes in statistical characteristics due to the influence of predictors. The timeframe was adjusted to three months or similar to the previous correlation analysis, which consisted of DecemberJanuary-February (DJF), March-April-May (MAM), JuneJuly-August (JJA) and September-October-November (SON).

\section{Result and Discussion}

The previous chapter explains how a set of data can be statistically processed in AWGenSCP to create rainfall simulations along with changes in the predictor variable, that is, SST in the Nino 3.4 zone in the following six months (the SST prediction was obtained from the NCEP's coupled forecast system model version $2 / \mathrm{CFSv} 2$ model). In this case, backtesting was performed for each release of predictor data at the beginning of each month. Each release presents the SST projection in the Nino 3.4 zone for the next six months from the date of release. Furthermore, the simulation followed the six-month prediction data with reference to the time of release. More specifically, the beginning of this section explains how the predictor affects the statistical properties of rain data by analyzing the baseline data (19612000). Then, the synthetic and actual rainfall data were compared based on graphical representation and statistical tests, i.e., the student's t-test. 
Statistical properties of the rainfall data for weather generator model development

In this sub-section, the statistical properties of rainfall data are analyzed in relation to SST in the Nino 3.4 zone for the baseline period (1961-2000). The statistical parameters, consisting of the probability of rainy days and rain distribution, are compared. Rain distribution is characterized by the shape and scale parameters of the gamma distribution. Also, the two periods, each representing the highest (SON) and lowest correlation (DJF), are compared.

Figure 3 shows the plots of the probability of rain days against the SST anomalies in the Nino 3.4 zone for each rain station in SON (the beginning of the rainy season). Point clouds in the picture lean towards the bottom-right of the chart, indicating that the probability of a rainy day increases when the SST anomaly in the Nino 3.4 zone is negative (LaNina). Conversely, when the SST anomalies in this zone are high, the probability of rainy days tends to decrease.

Figure 4 is a graph showing the relation between the probability of rainy days and the SST anomaly in the Nino 3.4 zone in DJF (peak of the rainy season). Unlike Figure 3, the point clouds in this picture do not present a distinct trend. In DJF, points are clustered on the right or upward of $0.6(60 \%)$ probability of rainy days, and this pattern is different from that of SON. Both findings imply that rainfall in DJF is higher than the SON, but it is not affected by ENSO, as evidenced by the results of the correlation analysis (see Table 1). The causative factors are, among others, the presence of low-pressure centres in the study area as a product of the apparent motion of the sun, Madden-Julian Oscillation, and the Indian Ocean Dipole mode (Chowdhury \& Beecham, 2013; Izumo et al., 2014; Ummenhofer et al.,
2013).

The plots between the values of shape parameter (Gamma distribution) and SST anomalies in the Nino 3.4 zone in SON (the beginning of the rainy season) are presented in Figure 5. Contrary to the observable change in the probability of rainy days in the same months (Figure 2), the pattern of the shape parameter, as induced by ENSO, is less than obvious. Its values are randomly distributed over the positive and negative SST anomalies. This condition is also apparent in DJF (the peak of the rainy season), as seen in Figure 6. Although a random distribution appears in DJF, the point clouds lean toward higher values of shape parameter than the ones in SON. It signifies a higher variation of daily rain distribution at the peak (DJF) rather than at the beginning (SON) of the rainy season. The same case applies to the amount of daily rainfall, which is higher in the former than the latter. Nevertheless, changes in the shape parameter-a statistical characteristic - at the peak of the rainy season are influenced more by the conditions of the season itself than the effect of ENSO.

Figures 7 and 8 are plots between the scale parameter of Gamma distribution and SST anomalies in the Nino 3.4 zone in two periods, SON and DJF. In general, the observed pattern is similar to that of the shape parameter, that is, random. Furthermore, point clouds of the scale parameter in DJF display a more apparent tendency toward the right side of the chart than in SON. The effect of ENSO on the distribution of the scale parameter is not sharply defined, which is the same as the shape parameter. That said, increased variation in daily rainfall is solely determined by the effects of the season itself (the peak of the rainy season).

Based on the analysis of the probability of rainy days and

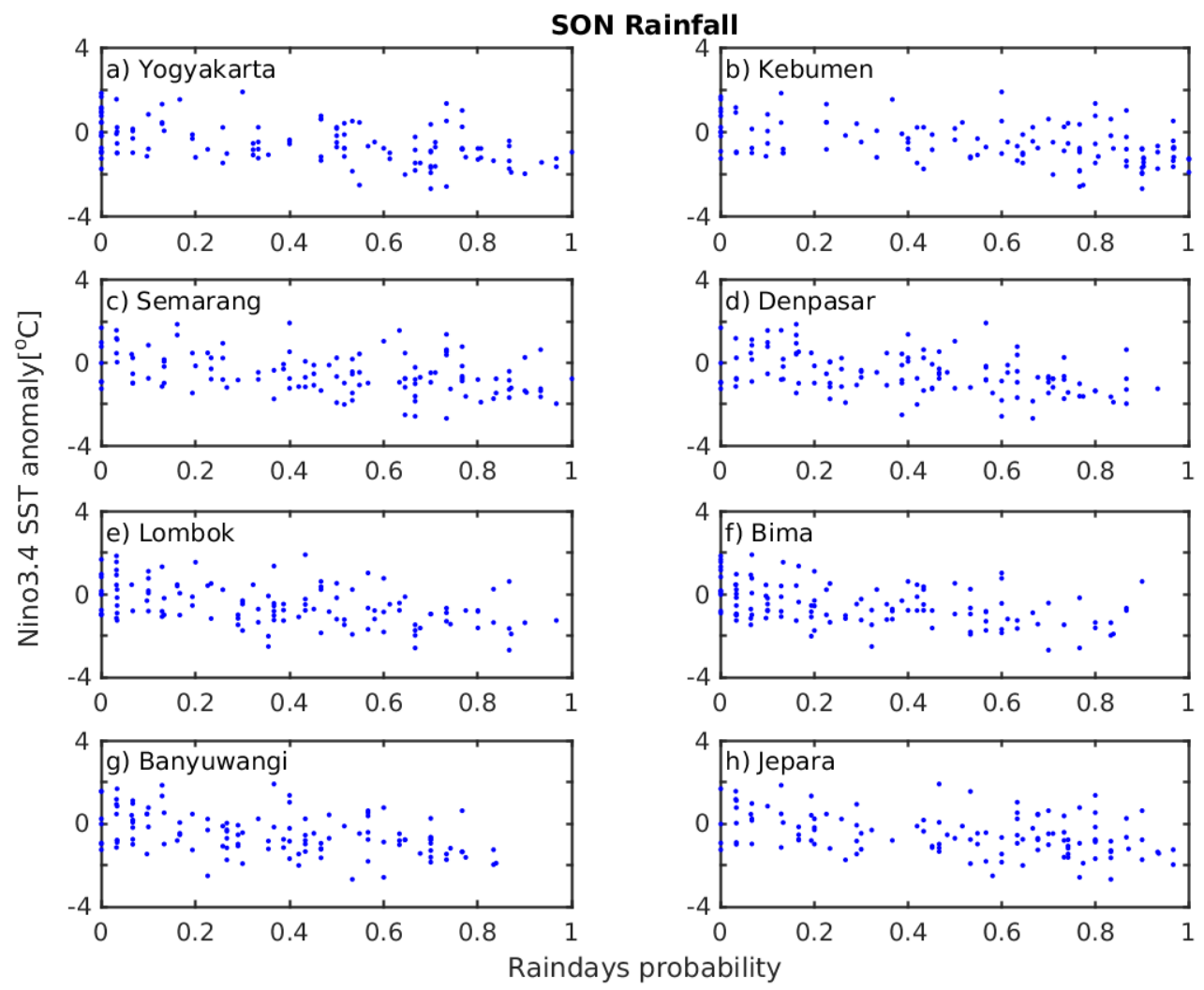

Figure 3. Plots of the probability of rainy days (x-axis) against SST anomalies in the Nino 3.4 zone (y-axis) for each observed rain station in SON (the beginning of the rainy season). Source: Data analysis 
DJF Rainfall
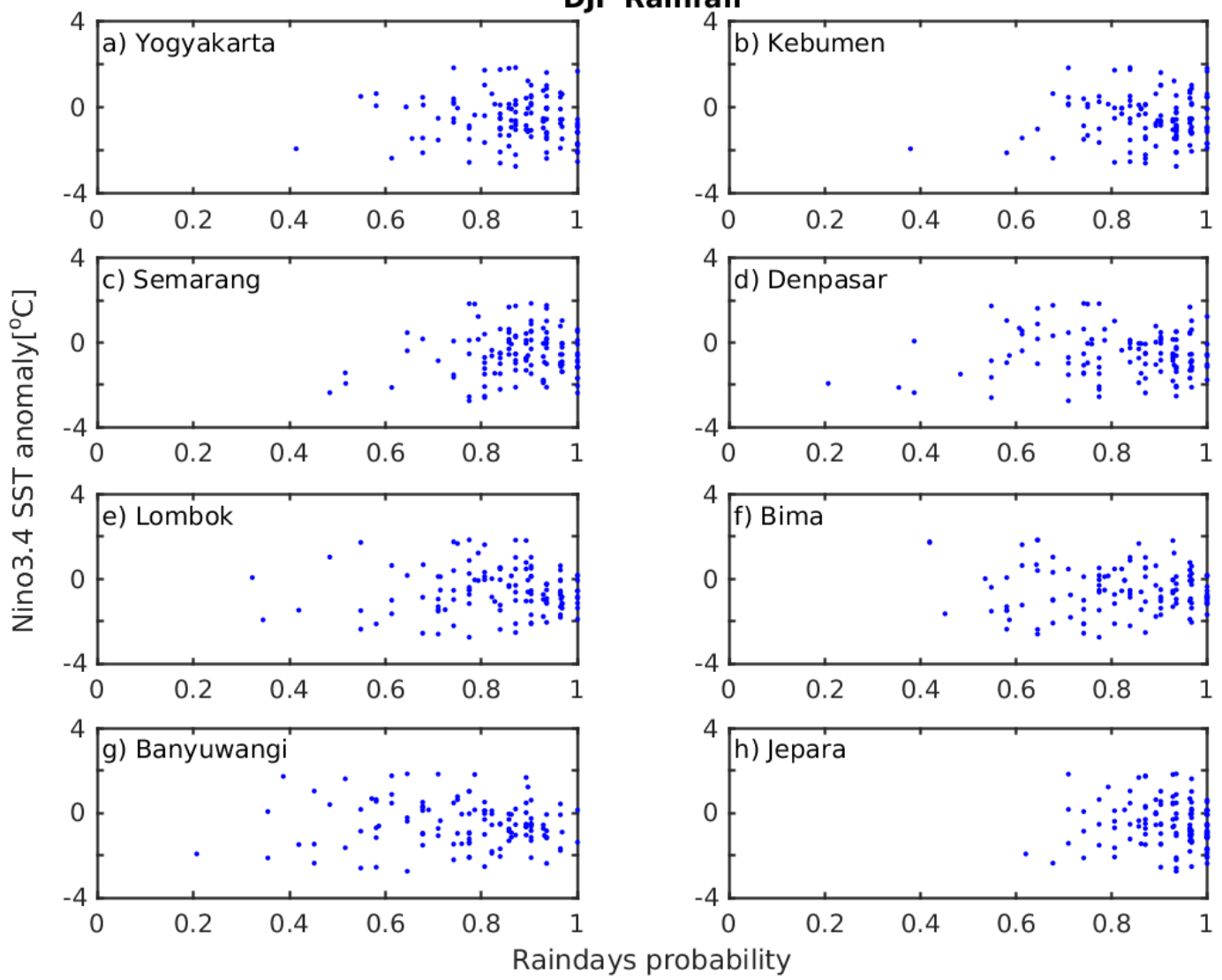

Figure 4. Plots of the probability of rainy days (x-axis) against SST anomalies in the Nino 3.4 zone (y-axis) for each observed rain station in DJF (the peak of the rainy season). Source: Data analysis

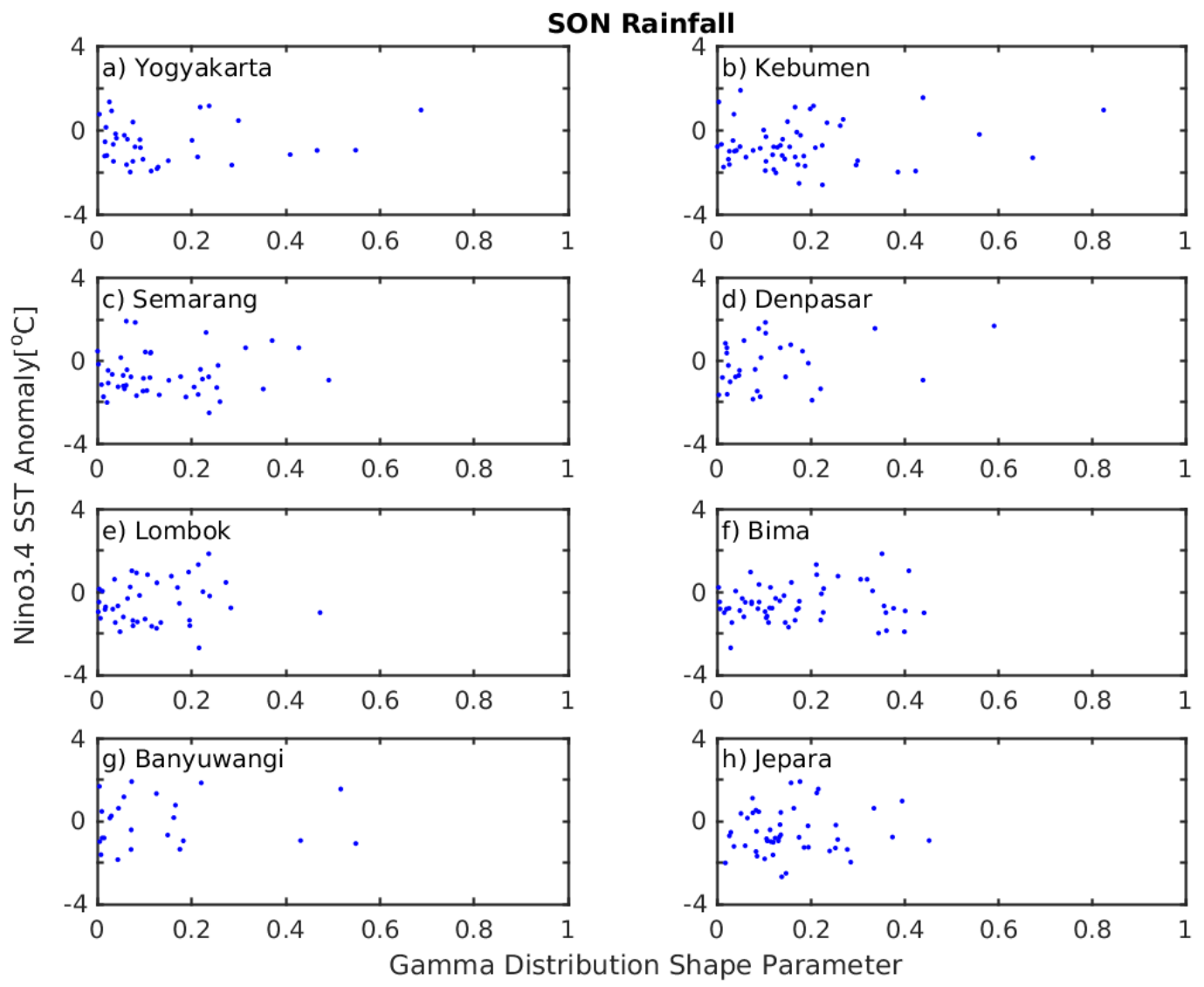

Figure 5.Plots of the shape parameter of Gamma distribution (x-axis) against SST anomalies in the Nino 3.4 zone (y-axis) for each observed rain station in SON (the beginning of the rainy season). Source: Data analysis 


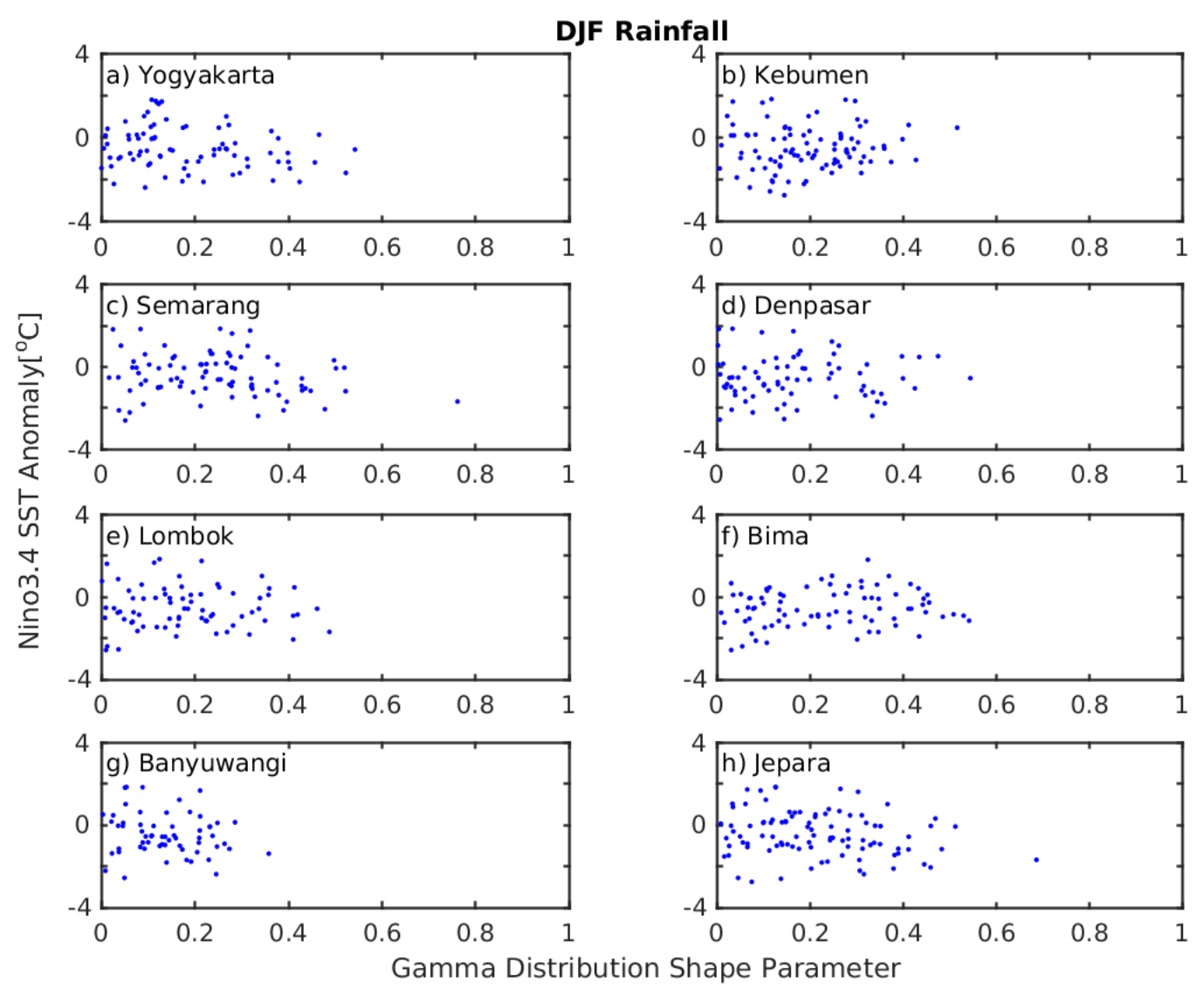

Figure 6. Plots of the shape parameter of Gamma distribution (x-axis) against SST anomalies in the Nino 3.4 zone (y-axis) for each observed rain station in DJF (the peak of the rainy season). Source: Data analysis

\section{SON Rainfall}
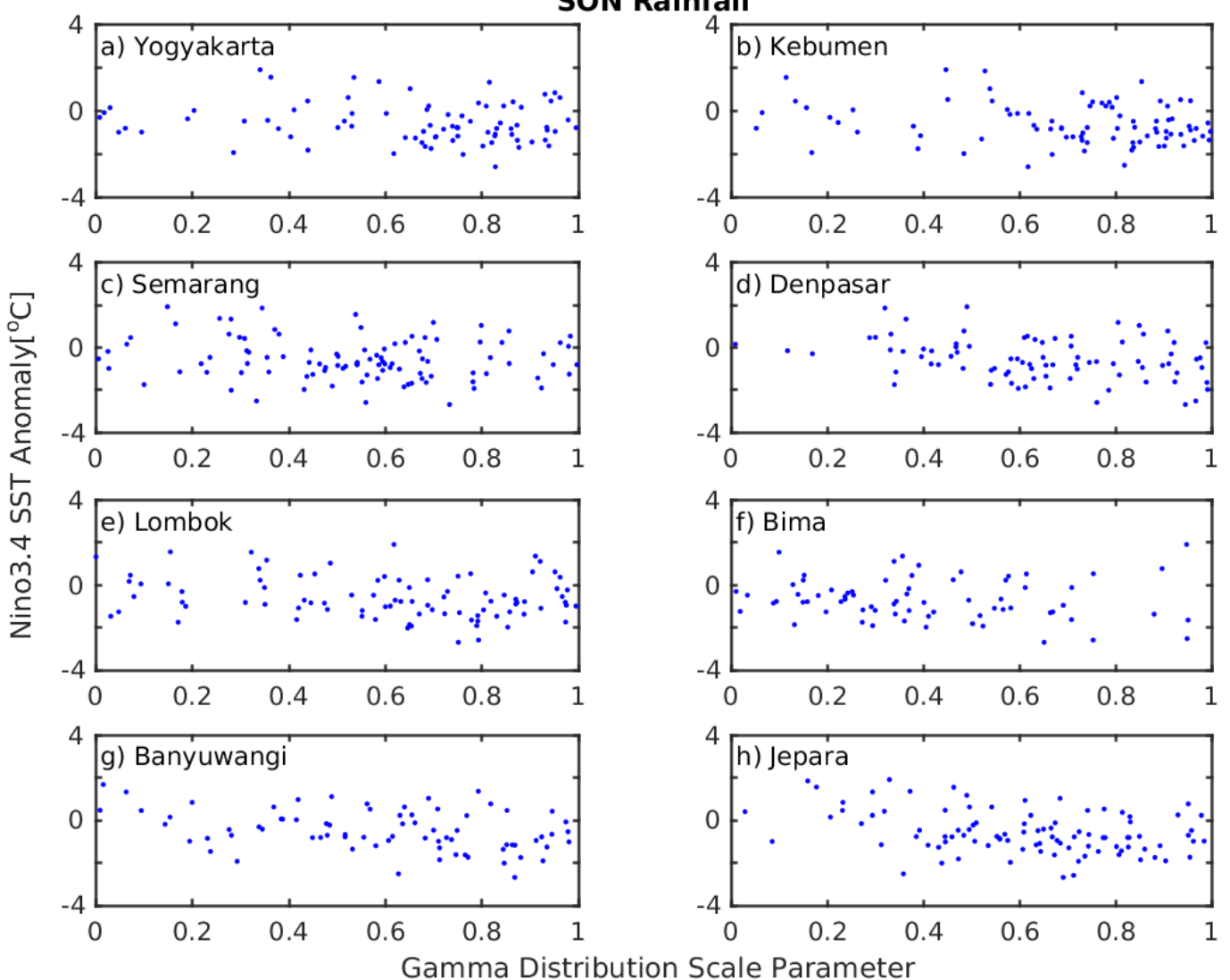

Figure 7. Plots of the scale parameter of Gamma distribution (x-axis) against SST anomalies in the Nino 3.4 zone (y-axis) for each observed rain station in SON (the beginning of the rainy season). Source: Data analysis 


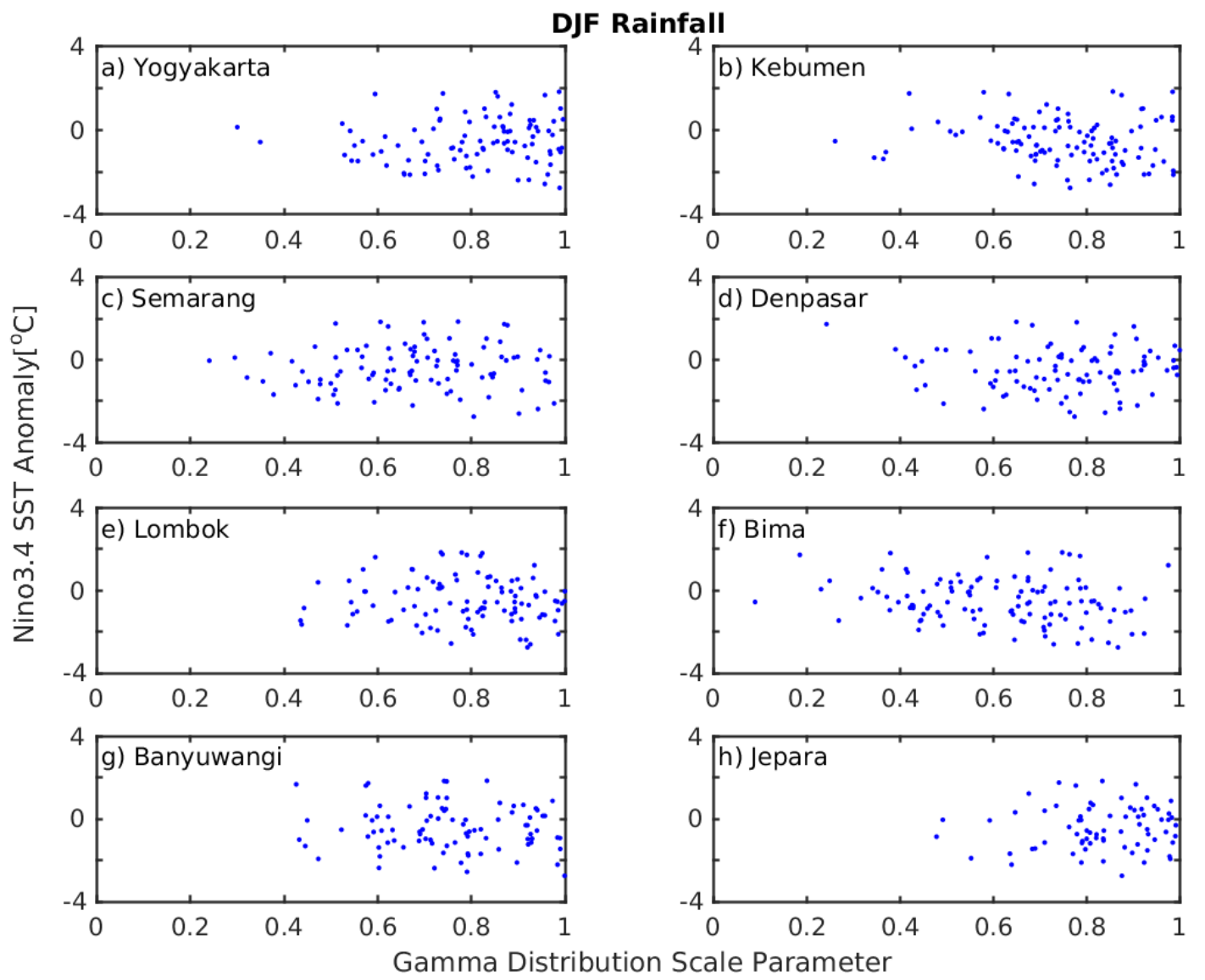

Figure 8. Plots of the scale parameter of Gamma distribution (x-axis) against SST anomalies in the Nino 3.4 zone (y-axis) for each observed rain station in DJF (the peak of the rainy season). Source: Data analysis

the shape and scale parameters of Gamma distribution, this study concludes that ENSO can affect the occurrence of rainfall in an area but not its amount. Declining trend, as shown in Figure 3 and Figure 4 indicates that an increase of the SST anomaly by $1^{\circ} \mathrm{C}$ reduce the rainfall probability from $25 \%$ to $50 \%$. In the AWGenSCP model, ENSO was found to influence any changes in the probability of rainy days, which implies that changes in the modelled probability correspond to the SST anomalies in the Nino 3.4 zone (Sekaranom \& Nurjani, 2019). In the cases where ENSO did not affect the existing statistical variables, namely the shape and scale parameters, the values of which were determined randomly according to the statistic characteristics of each period (Sekaranom \& Nurjani, 2019). Therefore, although the effects of ENSO on the shape and scale parameters in SON and DJF are not apparent, the predicted values can vary according to the distribution of the point clouds in the chart above.

\section{Model experimentation and validation}

Synthetic daily rainfall data in the AWGenSCP model was determined using three parameters discussed earlier, namely the probability of rainy days and the shape and scale parameters of Gamma distribution. Based on the previous results, the probability of rainy days, especially in SON, is greatly influenced by ENSO. Some other parameters have different statistical characteristics in each period. In this subsection, the trials and validation results of the developed models are discussed. The trial or experimentation used the data in 2001-2007 and was performed for all predetermined rain stations.

Figure 9 plots the synthetic rain data generated by the AWGenSCP model and the records of actual rainfall in 20012007 for comparison. The synthetic daily rain data was accumulated into monthly data, marked with the blue line. For comparison, the actual rain data is depicted in bar charts. The figure shows that the synthetic rainfall can simulate low and high rainfall each in the dry and rainy season. Comparisons in the rainy season showed varied results for different locations and times. As an example, the synthetic rainfall at the beginning of the rainy season in 2002 is higher than the actual record at Yogyakarta (a), Kebumen (b), Semarang (c) and Jepara (h) rain stations. This finding is potentially attributable to other factors besides ENSO, producing a relationship that is not always linear (Chowdhury \& Beecham, 2013; Izumo et al., 2014; Ummenhofer et al., 2013). The non-linear relationship indicates that precipitation in those areas not only affected by ENSO, but also affected by shorter and longer atmospheric perturbation working together at the same location, for example, Madden-Jullian Oscillation (MJO) and Indian Ocean Dipole Mode (IOD) (Sekaranom, Suarma, \& Nurjani, 2020).

The student's t-test determined whether the distributions of the daily synthetic and actual rainfall data were statistically homogeneous. In this case, homogeneity means that the simulation results can be used for further applicable analysis. The extent to which this model can be used depends on the results of the student's t-tests in two periods, namely El-Nino 

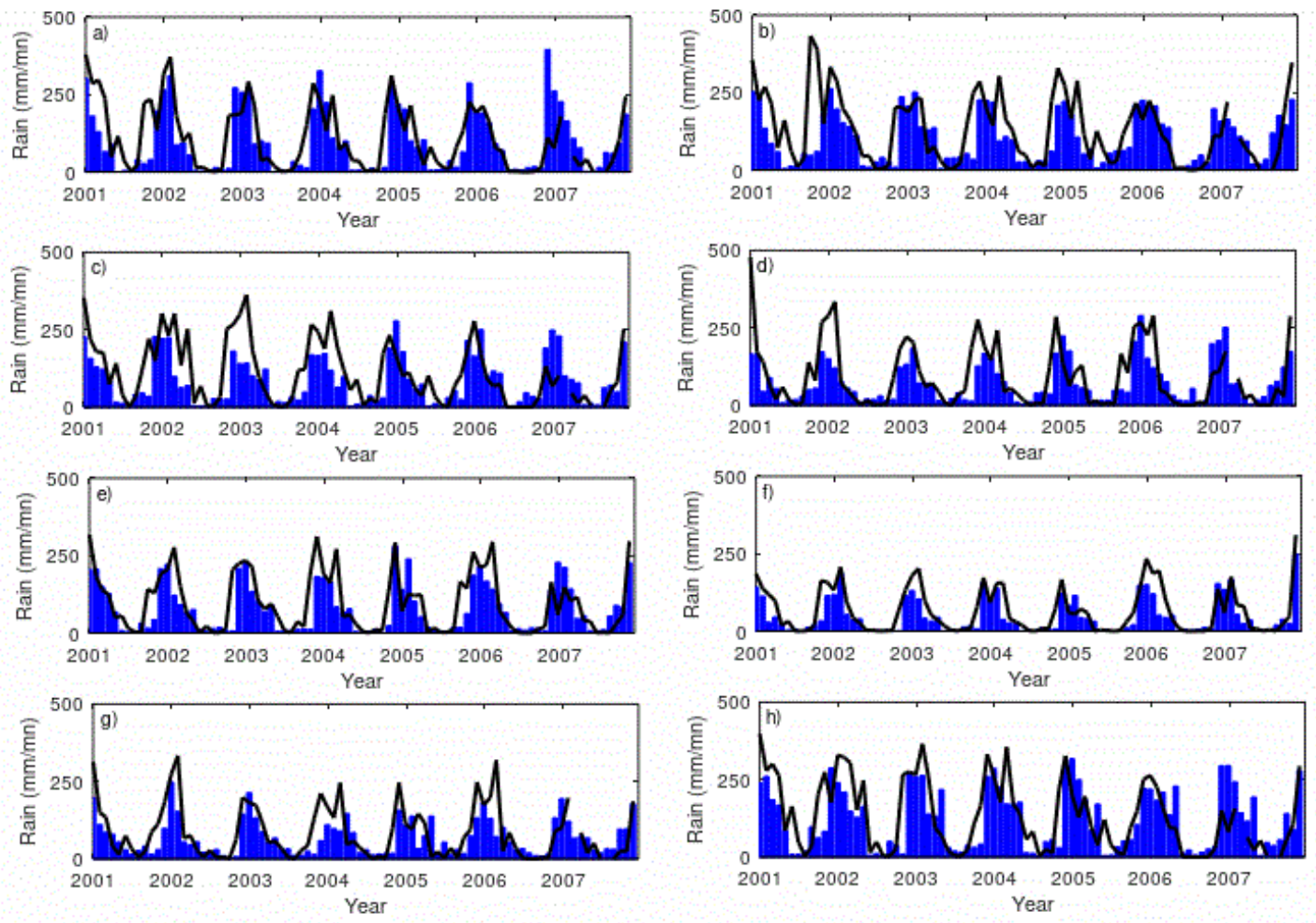

Figure 9. Plots of synthetic rainfall (line) and actual rainfall (bars) accumulated into monthly data in 2001-2007. From top to bottom: a) Yogyakarta, b) Kebumen, c) Semarang, d) Denpasar, e) Lombok, f) Bima, g) Banyuwangi, and h) Jepara rain stations. Source: Data analysis

Table 2. The results of the homogeneity test between synthetic and actual daily rainfall using the student's t-test for the El-Nino and La-Nina periods. The sample size is $>100$, with a 95\% confidence level and a critical value of $+/-1.645$. Bold font marks scores above the critical values (Source: Data analysis)

\begin{tabular}{llrr}
\hline & & Stations & Student's t-test scores \\
\cline { 3 - 4 } & & El-Nino period & La-Nina period \\
\hline A & Yogyakarta & 0.98 & 0.08 \\
B & Kebumen & 1.11 & 1.17 \\
C & Semarang & 0.94 & 2.37 \\
D & Denpasar & 1.34 & 0.006 \\
E & Lombok & 1.09 & 0.85 \\
F & Bima & 1.38 & 0.87 \\
G & Banyuwangi & 1.16 & 0.21 \\
H & Jepara & 0.44 & 1.02 \\
\hline
\end{tabular}

and La-Nina. For each period, the sample size was more than 100. Therefore, to achieve a $95 \%$ confidence level, the data is said to be homogenous if its critical value is between $+/$ 1.645. In general, the student's t-test scores were lower during La-Nina, except for Kebumen, Semarang and Jepara. In Semarang, these scores were higher than the critical values, meaning that the synthetic daily rainfall cannot resemble the actual rain data. As explained in the previous paragraph, these results can be caused by other weather factors. In particular, this region is a coast that is heavily influenced by land and sea winds (Qian, 2008).

\section{Conclusion}

Compared to other weather generator model, the development of the AWGenSCP model primarily lies in the adopted consideration, that is, how a large-scale predictor can affect local weather and climate. This effect can be a downscaling variable in the modelling of temporal changes in local weather and climate parameters. In this case, the large-scale predictor is not necessarily ENSO variability, but 
it can be another global-scale variable, for example, regionalscale wind speed, humidity, and other factors that are correlated with local weather and climate. Therefore, the developed model can be predictive for, among others, the downscaling of climate change impact.

Some recent weather generator models also incorporate a large-scale predictor in their analyses and assume that the regional and local systems share components of linearity. An example includes the positive relationship between temperature and rainfall, in which a rise in the former is believed to increase the latter. However, the relationship between the two weather and climate parameters is often non -linear. For this reason, current weather and climate observations confirm that although temperatures continue to increase, rainfall in the dry season becomes drier, but its intensity in the rainy season is increasingly higher (Iglesias \& Garrote, 2015; Meinke \& Stone, 2005). This assertion confirms the non-linear response of the local weather and climate systems. The AWGenSCP model has been developed to capture non-linear patterns, which are changes in the statistical distribution of the data (Sekaranom \& Nurjani, 2019). This aspect distinguishes AWGenSCP from the previously developed weather generator models that integrate stagnant statistical properties from time to time.

This study has proven that in several locations, ENSO affects the probability of rainy days. However, the same case does not apply to the shape and scale parameters of Gamma distribution. In conditions where the effects of large-scale predictors are statistically insignificant, the developed model executes the simulation based on a stagnant statistical distribution like weather generator models in general. On the contrary, when their influence on local weather and climate is statistically significant, changes in statistical probability and distribution can be incorporated in the calculation of the model (Sekaranom \& Nurjani, 2019). Experimentation in several ENSO-affected locations indicates that the model has successfully simulated low and high rainfall each in the dry and rainy season, which is similar to the records of actual rainfall. As for the student's t-test, it mostly shows that the synthetic and actual daily rain data have homogenous characters. In other terms, the model is potential for wider applications in any field related to hydrology and hydrometeorology.

Experimentation has also provided clues regarding future model development. It is mainly related to the results of the $t$ -test analysis, which are non-homogeneous, and is attributable to the influence of weather and climate on a regional scale other than ENSO, such as the Indian Ocean Dipole mode and Madden-Julian Oscillation (Chowdhury \& Beecham, 2013; Izumo et al., 2014; Ummenhofer et al., 2013). Nowadays, the developed AWGenSCP model solely depends on one large-scale predictor and, thereby, does not take into account the role of other variables. Model development that involves several large-scale predictors can potentially increase the accuracy of the model in the future.

\section{Acknowledgement}

This research receives funding from the "Higher Education Applied Research (PTUPT)" grant by the Ministry of Research, Technology and Higher Education of the Republic of Indonesia in 2019 with the title "Development of Articulated Weather Generator System for Seasonal Climate Prediction (AWGenSCP) for the Decision-Making Process in the Adaptation Pattern of Local Agriculture to Climate Change (Pengembangan Sistem Articulated Weather Generator for Seasonal Climate Prediction (AWGenSCP) Untuk Proses Decision-Making Pola Adaptasi Pertanian Lokal Dalam Menghadapi Perubahan Iklim). " This study is supported by available SST prediction data for the Nino 3.4 zone from the NCEP coupled forecast system model version 2 (CFSv2 model). The CFSv2 model is available online and accessible at http://www.cpc.ncep.noaa.gov/products/CFSv2/ CFSv2seasonal.shtml.

\section{References}

Chowdhury, R. K., \& Beecham, S. (2013). Influence of SOI, DMI and Niño3.4 on South Australian rainfall. Stochastic Environmental Research and Risk Assessment, 27(8), 19091920. https://doi.org/10.1007/s00477-013-0726-X

Chung, C. T. Y., \& Power, S. B. (2014). Precipitation response to La Niña and global warming in the Indo-Pacific. Climate Dynamics, 43(12), 3293-3307. https://doi.org/10.1007/ s00382-014-2105-9

Grimm, A. M., \& Tedeschi, R. G. (2009). ENSO and extreme rainfall events in South America. Journal of Climate, 22(7), 15891609. https://doi.org/10.1175/2008JCLI2429.1

Iglesias, A., \& Garrote, L. (2015). Adaptation strategies for agricultural water management under climate change in Europe. Agricultural Water Management, 155, 113-124.

Ivanov, V. Y., Bras, R. L., \& Curtis, D. C. (2007). A weather generator for hydrological, ecological, and agricultural applications. Water Resources Research, 43(10). https:// doi.org/10.1029/2006WR005364

Izumo, T., Lengaigne, M., Vialard, J., Luo, J. J., Yamagata, T., \& Madec, G. (2014). Influence of Indian Ocean Dipole and Pacific recharge on following year's El Niño: Interdecadal robustness. Climate Dynamics, 42(1-2), 291-310. https:// doi.org/10.1007/s00382-012-1628-1

Jourdain, N. C., Gupta, A. Sen, Taschetto, A. S., Ummenhofer, C. C., Moise, A. F., \& Ashok, K. (2013). The Indo-Australian monsoon and its relationship to ENSO and IOD in reanalysis data and the CMIP3/CMIP5 simulations. Climate Dynamics, 41(11-12), 3073-3102. https://doi.org/10.1007/ s00382-013-1676-1

Marfai, M. A., Sekaranom, A. B., \& Cahyadi, A. (2015). Profiles of marine notches in the Baron coastal area-Indonesia. Arabian Journal of Geosciences, 8(1), 307-314. https:// doi.org/10.1007/s12517-013-1232-7

Marfai, M. A., Sekaranom, A. B., \& Ward, P. (2015). Community responses and adaptation strategies toward flood hazard in Jakarta, Indonesia. Natural Hazards, 75(2), 1127-1144. https://doi.org/10.1007/s11069-014-1365-3

Meinke, H., \& Stone, R. C. (2005). Seasonal and inter-annual climate forecasting: The new tool for increasing preparedness to climate variability and change in agricultural planning and operations. In Increasing Climate Variability and Change: Reducing the Vulnerability of Agriculture and Forestry (pp. 221-253). https:// doi.org/10.1007/1-4020-4166-7_11

Nurjani, E., Harini, R., Sekaranom, A.B., \& Mutaqqin, A.S. (2020). Tobacco farmers Perspective towards increasing climate change risk on agriculture sector: a case study of Temanggung-Indonesia. IOP Conference Series: Earth and Environmental Science, 451(1). https://doi.org/10.1088/1755$1315 / 451 / 1 / 012101$

Qian, J. H. (2008). Why precipitation is mostly concentrated over islands in the maritime continent. Journal of the Atmospheric Sciences, 65(4), 1428-1441. https:// doi.org/10.1175/2007JAS2422.1

Richardson, C. W., \& Wright, D. A. (1984). WGEN: A Model for 
Generating Daily Weather Variables. In United States Department of Agriculture, Agriculture Research Service ARS8. Retrieved from ftp://ftp.biosfera.dea.ufv.br/users/ francisca/Franciz/papers/Richardson \& Wright.pdf

Sekaranom, A. B., \& Masunaga, H. (2017). Comparison of TRMMderived rainfall products for general and extreme rains over the maritime continent. Journal of Applied Meteorology and Climatology, 56(7), 1867-1881. https://doi.org/10.1175/ JAMC-D-16-0272.1

Sekaranom, A. B., \& Masunaga, H. (2019). Origins of heavy precipitation biases in the TRMM PR and TMI products assessed with cloudsat and reanalysis data. Journal of Applied Meteorology and Climatology, 58(1), 37-54. https:// doi.org/10.1175/JAMC-D-18-0011.1

Sekaranom, A. B., \& Nurjani, E. (2019). The development of Articulated Weather Generator model and its application in simulating future climate variability. IOP Conference Series: Earth and Environmental Science, 256(1). https:// doi.org/10.1088/1755-1315/256/1/012044

Sekaranom, A. B., Nurjani, E., Hadi, M. P., \& Marfai, M. A. (2018). Comparsion of TRMM Precipitation Satellite Data over Central Java Region - Indonesia. Quaestiones Geographicae, 37(3), 97-114. https://doi.org/10.2478/quageo-2018-0028

Sekaranom, A. B., Nurjani, E., \& Pujiastuti, I. (2018). Cloud structure evolution of heavy rain events from the East-West Pacific Ocean: A combined global observation analysis. IOP
Conference Series: Earth and Environmental Science, 148(1). https://doi.org/10.1088/1755-1315/148/1/012006

Sekaranom, A.B., Suarma, U., \& Nurjani, E. (2020). Climate extremes over the maritime continent and their associations with Madden-Jullian Oscillation. IOP Conference Series: Earth and Environmental Science, 451(1).https:// doi.org/10.1088/1755-1315/451/1/012006

Ummenhofer, C. C., D'Arrigo, R. D., Anchukaitis, K. J., Buckley, B. M., \& Cook, E. R. (2013). Links between Indo-Pacific climate variability and drought in the Monsoon Asia Drought Atlas. Climate Dynamics, 40(5-6), 1319-1334. https://doi.org/10.1007/s00382-012-1458-1

Wilby, R. L. (1999). The weather generation game: A review of stochastic weather models. Progress in Physical Geography, Vol. 23, pp. 329-357. https:// doi.org/10.1191/030913399666525256

Wilks, D. S. (1999). Multisite downscaling of daily precipitation with a stochastic weather generator. Climate Research, 11 (2), 125-136. https://doi.org/10.3354/cr011125 